\title{
Biodegradable Food Container Made of Abaca Fiber Pulp with Beeswax Biocoating
}

\author{
Wafaa Letya Jahroo ${ }^{1 *}$, Muhammad Dzulfiqar C. A. ${ }^{2}$, Sabrina Ilma Sakina ${ }^{3}$ \\ ${ }^{1}$ Institut Teknologi Bandung, Indonesia \\ ${ }^{2}$ Institut Teknologi Yogyakarta, Indonesia \\ ${ }^{3}$ Institut Teknologi Bandung, Indonesia \\ *Corresponding author.Email:wafaajahroo@students.itb.ac.id
}

\begin{abstract}
In the long term, the use of materials that are not environmentally friendly such as styrofoam as the main ingredient in food containers is dangerous. Therefore, an environmentally friendly and natural substitute is needed to replace Styrofoam. Abaca fiber (Musa Textilis) is a natural fiber obtained from plant stems (bark fiber). Utilizing decortication, abaca fiber bundles can be obtained. The fiber is processed into paper pulp and designed as a food container. The use of beeswax as a bio-coating can make raw materials waterproof and, of course, safe for food. Beeswax (Cera Alba) is a natural wax produced by honey bees of the genus Apis; it has been considered the first plastic as a lubricant and water-repellent agent. Beeswax is approved for food use in most countries and the European Union under E number E901. The Abaca food container tested has a capacity of 1,172.5 cm 3 which can accommodate three types of food, namely rice, fried chicken, and vegetables. The durability that is owned shows the material's resistance, which remains intact for 24 hours of experimentation. However, the absorption capacity of abaca food containers is less able to hold oil for 24 hours. The method used is a qualitative method with additional design exploration, which prioritizes the process carried out during the research to determine whether the resulting product can have better quality. Abaca food containers can be an alternative to food containers made from bio-materials and eco-friendly.
\end{abstract}

Keywords: Abaca fiber pulp, Biodegradable, Beeswax, Food container, Design.

\section{INTRODUCTION}

Every year the use of food containers is increasing. According to the US Environmental Protection Agency (EPA), food container materials make up almost half of all municipal solid waste [1]. More than 63 percent of the 258 million tons of substantial municipal trash created in the United States in 2014 was made up of packaging materials (for food and other purposes), with only 35 percent ( 89 million tons) recycled or composted [2].

For years, people have debated the possible dangers of Styrofoam containers. It is a topic that's likely to get more attention during this coronavirus outbreak. Take-out meals have increased in the last eight months of COVID-19, with many delivered in Styrofoam boxes. When the containers are heated, harmful substances may leak into the food, posing a health risk. Of course, the garbage generated is not biodegradable, resulting in environmental damage [3].

An alternative to overcome this problem is to replace the basic material of food containers by using bio-materials because the decomposition time is short. Currently, the use of food containers that are biomaterial made of cardboard. Paperboard made from pulp made from wood fiber/cellulose. The environmental impact generated by the manufacture of pulp and paper results mainly from wood pulping and pulp bleaching. In pulping processes, sulfur compounds and nitrogen oxides are emitted to the air, and during pulp bleaching, chlorinated and organic compounds and nutrients are discharged to the wastewaters. The environmental impact of paper manufacture is lower, wastewater discharge being the most important source of pollution [4]. Natural fiber is a raw material that can replace wood fiber, one of which is abaca fiber. 
Paper pulp from abaca fiber has the potential to be a source of raw material for making environmentally friendly food containers. For this purpose, the abaca fiber is ground first before being formed into paper, which is then shaped into a food container. However, the drawback of this raw material is that it is not waterproof. This can be overcome by coating the raw material using appropriate bio-coating. Beeswax can be used as a bio-coating to make raw materials waterproof and, of course, food safe. Because it is a natural commercial wax with high hydrophobicity and excellent moisture resistance, beeswax has been widely employed as a food-grade addition in cosmetics, medicines, and meals [5].

When the concentration of chitosan in solution increased from 1.0 to $3.0 \mathrm{wt}$ percent, the water vapor transport rate decreased from 171.6 to $52.8 \mathrm{~g} / \mathrm{m} 2 / \mathrm{d}$, while the beeswax coating weight was simultaneously reduced (from 10.1 to $4.9 \mathrm{~g} / \mathrm{m} 2$ ), the double paper coating with chitosan-beeswax combination served as a water vapor barrier [6].

Packaging is critical for preserving food quality, avoiding food waste, and lowering preservatives in food. The packaging performs the essential purpose of confining the food, safeguarding it from chemical and physical damage, and giving customers and marketers important information [7]. It is necessary to have a functional design, which can store food in large quantities and is effective in its manufacture; it does not require other materials, such as glue, by using a lock on the packaging.

This paper aims to demonstrate that food containers can be replaced with environmentally friendly bio-materials and innovative designs. Abaca food container with beeswax as a bio-coating is a new product that can be used as an alternative to help overcome environmental pollution from styrofoam. In addition to biodegradable raw materials, abaca food containers are designed with benefits and functions to meet the needs.

\subsection{Objective}

The main objective of this research is to identify the existence of abaca fiber products produced in the market. The purpose is to identify the potential area of a new product i.e food container to be developed. To experiment and analyze the abaca fiber and beeswax bio coating. The Abaca fiber will be experimented by using handmade papermaking method and make it into certain thicknesses of paper to get the texture and the results later will then be analyzed. To propose and prototype. By using a product design approach, the design will be proposed and developed to suit the outcome of the experiment. By implementing the selected experimented result of abaca fiber, the prototype will be the new form and area of product as compared to the existing abaca fiber-based products.

\subsection{Methods}

This study uses a qualitative method with additional design exploration. Collecting data in this study using observation. Observations were made at the same time and the same treatment for the two products. There was no different treatment for styrofoam and abaca food containers.

A qualitative method is an analytical and descriptive method by prioritizing the process carried out during research to determine whether the resulting product can have better quality. The research will be conducted by observing the durability, absorption, and capacity of the product. Observations were made to compare the resistance, absorption, and capacity of styrofoam with abaca food containers using the same number of minutes and types of food without different treatments. The three categories used for these observations refer to food packaging and food container packaging as disclosed by QIMA. QIMA is a company that works in the field of quality control of goods. QIMA inspectors and lab technicians conduct thorough product inspections and tests for the following categories of food containers, packaging, and food contact items that are made of plastic, metal, and wood. QIMA inspectors and lab technicians conduct the following checks to ensure the quality and safety of your food contact items:

1. Visual examination and evaluation

2. Dimensions check

3. Sensory testing and taint analysis

4. Physical hazard assessment

5. Color bleeding

6. Composition check

7. Overall and specific migration tests

8. Non-intentionally added substances (NIAS)

9. Volatile organic compounds

10. Heavy metals (extractable and leachable)

11. Residual monomers and solvents

12. Impurities and byproducts

13. REACH SVHC (Substances of Very High Concern)

Supply chain intelligence: receive supplier and quality information in real-time; industry-leading response time for audits, testing, and inspections are just a few of the reasons why researchers pick QIMA as a research reference. Manage your orders and access your data from anywhere, with any team. All-inclusive 
pricing: flat fees for inspections and audits, immediate testing quotations, 2,500 auditors and inspectors, six in-house labs, and 85 countries of operation. Researchers chose only 3 things to observe, namely durability, absorption, and capacity of the product. The three things observed were based on statements from QIMA to check the quality of food containers, namely sensory testing and taint analysis of residual monomers and solvents, and composition check. The food container design also refers to the dimensions check and visual examination from QIMA according to the packaging standards set by the author.

The data used is evidenced by photo evidence before and after feeding. The food that will be used is processed chicken. Researchers chose chicken because chicken is the most commonly sold food and is easy to obtain. The product's durability will be seen by placing hot food that has just been cooked then closed and left for 24 hours, after which it will be reopened whether the stored food is stale or not. The absorption of the product will be seen by placing the chicken within 2 hours and then seeing how much oil is absorbed in the product. Finally, the product capacity will use chicken, rice, and fresh vegetables, then see which product can accommodate more food with an aesthetic arrangement.

This study uses a comparison qualitative method collecting data in this study using observation. Observations were made at the same time and the same treatment for the two products. There was no different treatment for styrofoam and abaca food containers. This study will compare two places to eat, namely abaca food containers with styrofoam.

Making paper pulp is divided into 4 stages; the first stage is the stage of scouring and teepol, which aims to soften and clean the abaca fiber from dirt and other congenital substances. In this process, the leaf fiber is boiled for 40 minutes in 2.5 liters of water per $\mathrm{kg}$ of fiber with the help of teepol as much as $12 \%$ of the weight of the fiber. The second stage is the bleaching stage and adding 40 grams of $\mathrm{H} 2 \mathrm{O} 2$. The next step is to cook it with 2.5 liters of water and add 35 grams of caustic soda $(\mathrm{NaOH})$. The last stage is the printing process; the pulp is stored in a tub and mixed with water in a ratio of 1:3 (fiber: water). The pulp is printed by inserting the screen into the tub. Fibers from the tub will be carried on the surface of the screen when the screen is lifted. The screen and the fibers that have been attached to the screen are dried in the open air to dry. The thickness chosen for the manufacture of the food container itself is approximately $2.5 \mathrm{~mm}$. Furthermore, the fibers attached to the wooden boards are dried in the open air. After the abaca pulp becomes paper, the next step is to coat the abaca paper with beeswax.

\section{FINDINGS}

\subsection{Abaca Food Container and Styrofoam Comparison}

Table 1. Abaca Food Container and Styrofoam Comparison

\begin{tabular}{|c|l|l|l|}
\hline No & Comparison & Abaca Food Container & Styrofoam \\
\hline 1. & Design & & \\
\hline 2. & Dimensions & $17,5 \times 10 \times 6,7 \mathrm{~cm}$ & \\
\hline 3. & Volume & $1.172,5 \mathrm{~cm} 3$ & $18 \times 18 \times 8 \mathrm{~cm}$ \\
\hline
\end{tabular}




\begin{tabular}{|c|c|c|c|}
\hline No & Comparison & Abaca Food Container & Styrofoam \\
\hline 4. & Durability & Lid can be opened 180 degrees & Lid can be opened 180 degrees \\
\hline 5. & Absorption & The oil spots appear after 24 hours & \\
\hline 6. & Capacity & & \\
\hline 7. & $\begin{array}{l}\text { The form of } \\
\text { packaging after } 2 \\
\text { hours of testing }\end{array}$ & & \\
\hline 8. & $\begin{array}{l}\text { The form of } \\
\text { packaging after } \\
24 \text { hours of } \\
\text { testing }\end{array}$ & & \\
\hline
\end{tabular}




\section{RESULT}

The paper pulp has been formed into a pattern to be combined into a food container, then coated with

beeswax to protect food with food-grade/food-safe materials. In addition, beeswax can protect the paper pulp from water or oil contained in the food. The results of observations prove this for 2 hours; abaca food containers are not damaged with the food used: rice, fried chicken, and vegetables. Beeswax also increases the durability of abaca food containers by coating them on the inside of the container.

The selection of types of food in the form of rice, fried chicken, and vegetables in the abaca food container experiment is a type of food that is abundant and easy to find in restaurants. These types of food also represent three ingredients in the form of carbohydrates, proteins, and nutrients. This is what underlies the selection of these types of food in the abaca food container experiment.

In terms of durability, abaca food containers can still protect the food inside for 24 hours. The integrity of the shape of the abaca food container also remains the same as before. However, within 24 hours, the bottom right of the fried chicken contained oil that slightly penetrated the surface of the abaca food container. In addition, abaca food containers are not very sturdy, so the food contents cannot be extensive. To increase the strength of the abaca food container, that is, by thickening the paper pulp.

The absorption capacity of abaca food containers for 24 hours containing rice, fried chicken, and vegetables cannot accommodate the water produced by the hot steam from the rice and the oil from the fried chicken. The observations show this for 2 hours, and abaca food container leaks a little on the bottom surface right on the fried chicken. During the 24 hours of the experiment, the oil from the fried chicken began to appear from the outside. In contrast to styrofoam, styrofoam does not appear to leak on the surface or walls. However, with the addition of coating the surface of the abaca food container using beeswax, the coated surface adds protection from water and oil that comes from the food.

The capacity obtained from the abaca food container is $1,172.5 \mathrm{~cm} 3$ with a patterned design. With this capacity, abaca food containers can accommodate several types of food such as carbohydrates, proteins, sauces, and vegetables. The pattern that has been designed produces a capacity that is almost the same as styrofoam. The design also makes it easier to carry, store, and use the container.

\subsection{Food Container Design Prototype}

Several design variations were made to see how paper from abaca material can be made into a food container with several variations according to user needs. In Fig. 1. Design is taken from the basic shape of an octagon which has 8 equal sides, with the addition of a semicircle on one side, which is used as a food container cover, no glue is needed because it already has its own lock. In Fig. 2. The second design has a more organic, and unique shape. There is no lock on this second design. In Fig. 3. In the third design, it is made in such a way that the rice can be arranged properly. The addition of a handle at the top of the food container is intended to make it easier for users to carry their food containers, thereby reducing plastic waste that is commonly used for wrapping.

Designs made as an alternative to other forms in the manufacture of food containers are made with origami patterns because abaca paper is easy to shape and sturdy. The bottom of the food container design also has different shapes according to user needs.

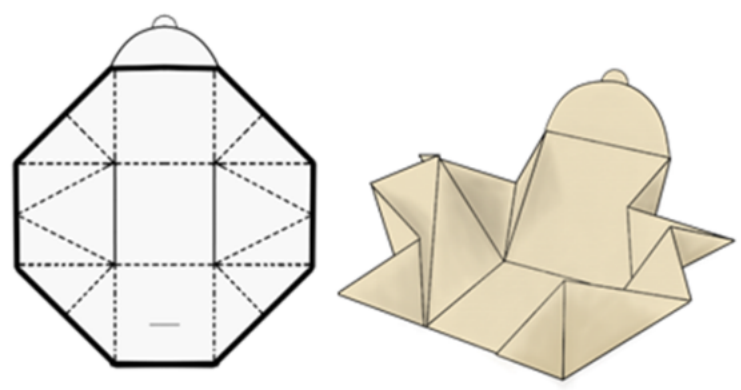

Figure 1. (a) Pattern Food Container; (b) Prototype Food Container
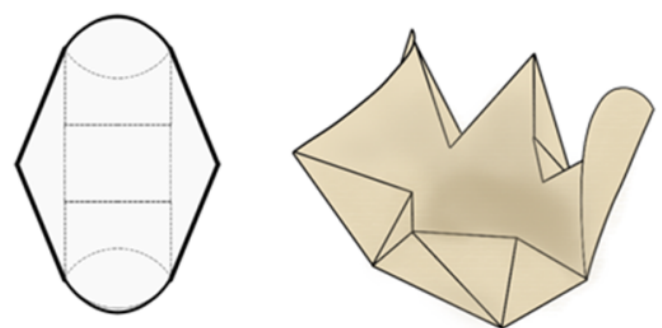

Figure 2. (a) Pattern Food Container; (b) Prototype Food Container 


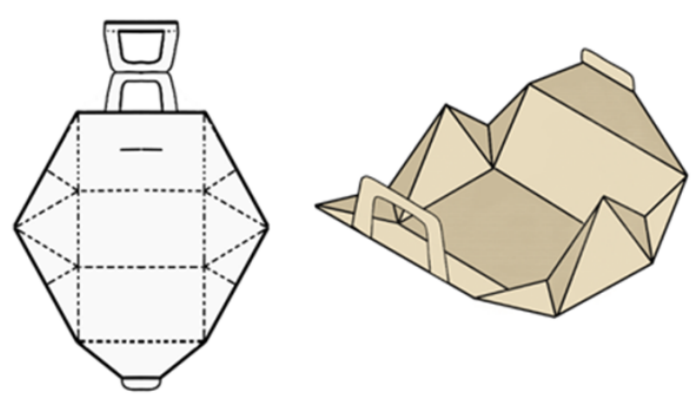

Figure 3. (a) Pattern Food Container; (b) Prototype Food Container

\section{CONCLUSION}

Abaca food containers after experiments using rice, fried chicken, and vegetables as research subjects show that abaca food containers are feasible or can be used as food containers that are bio-material and ecofriendly. This is because the experiment results show that in terms of durability, abaca food containers remained intact in the experiment for 24 hours without any damage to the material. In terms of capacity, the abaca food container has a volume of $1,172.5 \mathrm{~cm} 3$, covering three types of food. In terms of material resistance, abaca food containers have a strong character and are challenging to tear compared to food containers made from cardboard. These advantages can support food containers made from eco-friendly solid materials. However, the absorption capacity of abaca food containers shows poor results because oil can penetrate the surface of the material. Thus, abaca food containers can be an alternative to food containers made from bio-materials and eco-friendly.

For further research, food containers need to be made using a hot pressing system with a certain level of pressure and made suitable moldings for food containers with low absorption so that they can be used for soupy foods.

\section{ACKNOWLEDGEMENT}

This research was funded by LPPM ITB (Lembaga Penelitian dan Pengabdian kepada Masyarakat Institut Teknologi Bandung) through its 2021 PPM ITB grant.

\section{REFERENCES}

[1] U. Agency, Reducing Wasted Food \& Packaging, EPA, 2014.

[2] U. P. Agency, Advancing Sustainable Materials Management: Facts and Figures, EPA, 2017.
[3] S. J. W., Styrofoam Container Use On The Rise During COVID-19 Pandemic, November 2020.

[4] A.C. Puitel, Environmental impact of pulp and paper mills, in: Environmental Engineering and Management Journal, 2021, pp. 11(1):81-86.

[5] P. K. Y. W. J. Iewkittayakorna, Biodegradable plates made of pineapple leaf pulp, in: Journal of Materials Research and Technology, 2020, p. 2.

[6] X. H. Q. L. Z. W, Enhanced water vapour barrier and grease resistance of paper bilayer-coated with chitosan and beeswax, in: Carbohydr Polym, 2014, pp. 1-6.

[7] 2. I. C. o. F. a. B. Packaging, Importance of Food Packaging, in AGRI, FOOD \& AQUA, Italy, 2016. 